\title{
Investigation of the processes of adsorbent regeneration by compression heat in an adsorption dryer of compressed air
}

\author{
V. V. Kozlov ${ }^{(a)}$, E. S. Piskun ${ }^{(b)}, O . S$. Ilicheva ${ }^{(\mathrm{c})}$ \\ (a) Ltd ENECON-INGENEERING \\ Moscow, 105005, Russia, vladimir.kozlov@bmstu.ru

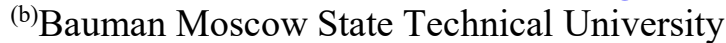 \\ Moscow, 105005, Russia, piskun@bmstu.ru \\ (c)Bauman Moscow State Technical University \\ Moscow, 105005, Russia, olga.ilicheva5@yandex.ru
}

\begin{abstract}
The results of numerical modeling of the processes of drying and regeneration of the adsorbent by heat of compression are presented on the example of the scheme of adsorption drying with the separation of the air flow on the stage of the cooling of the adsorbent. The dynamics of temperature and humidity parameters within the technological columns at all three stages of the adsorption and regeneration cycle was evaluated. It is shown that the considered scheme of adsorption drying allows to provide rather stable average dew point of the dried compressed air without losses on the adsorbent purging.
\end{abstract}

Keywords: compressor, adsorption desiccant, regeneration, numerical simulation of adsorption, desorption, cooling processes.

\section{INTRODUCTION}

The question of air drying in the process of compression is a relevant problem on the way to increase the energy efficiency of modern compressor technology [1], [2], [3] There is a sufficient number of types of technological equipment for drying compressed air. The classification of drying methods can be presented in the form of the following diagram. (fig. 1) [4]. 


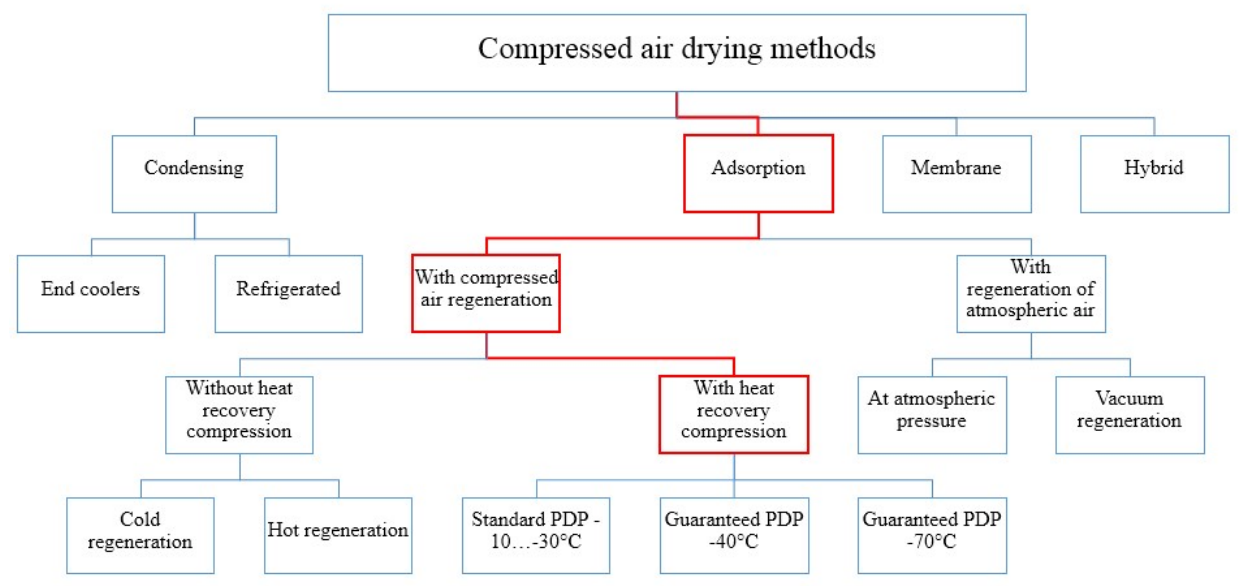

Figure 1. Compressed air drying methods

The paper examines a drying method that uses the heat of the compression to realize the most energy-consuming part of the adsorption drying cycle in high-productivity compressor stations, namely, the adsorbent regeneration process. The analysis of adsorption and regeneration technological processes is carried out on the example of the adsorption drying scheme with the separation of the air flow at the stage of cooling the adsorbent (fig. 2).
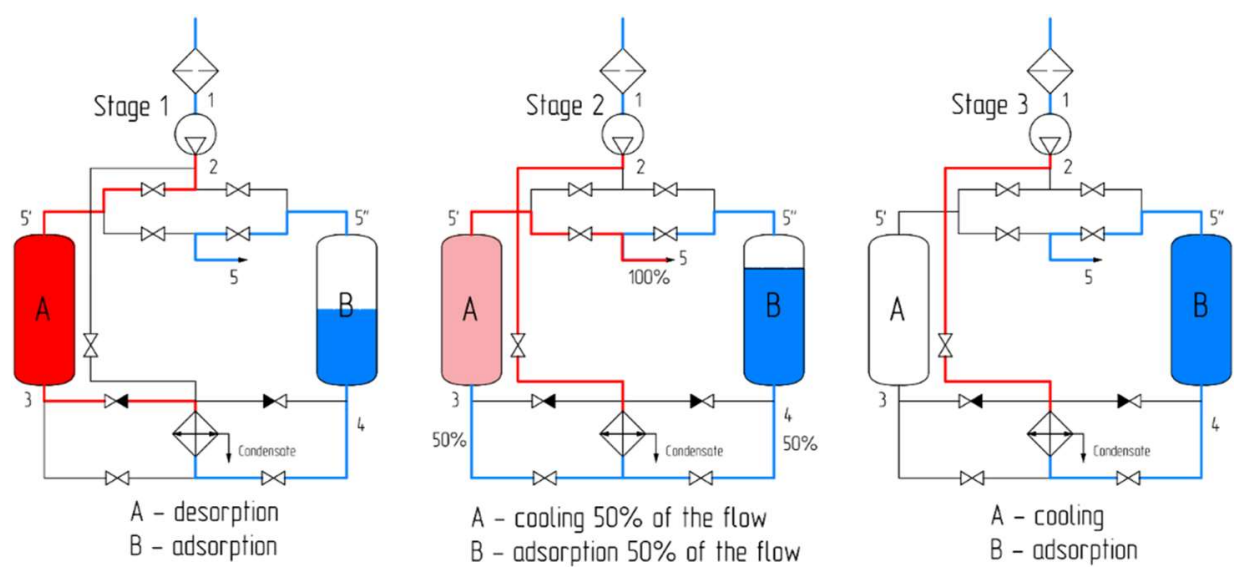

Figure 2. The technology of the adsorption drying with the separation of the air flow at the stage of cooling the adsorbent

\section{RESEARCH RESULTS}

During the technology under consideration heat and mass transfer processes within the drying and regeneration cycle are purely dynamic nature, due to the $\mathrm{A}$ and B columns switching.

The dynamic problem, according to many authors, has no analytical solution and can be solved only by numerical methods [5], [6], [7], [8]. 
Thus, a numerical method and a program for calculating the dynamics of heat and mass transfer during the adsorption drying of compressed air were selected as the key tool for a research [9].

The mathematical model of the calculation program is a system of equations describing the non-stationary process of changing the parameters of humidity and temperature in a one-dimensional setting on the height of the dryer column [9].

Mass balance equation

$$
\frac{d\left(d_{g}\right)}{d \tau}+\frac{d\left(d_{a}\right)}{d \tau}+\omega \frac{d\left(d_{g}\right)}{d x}=0
$$

where $d_{g}$ is moisture content of air in $\mathrm{g} / \mathrm{kg}, d_{a}$ is moisture content of adsorbent in $\mathrm{g} / \mathrm{kg}, \tau$ is time in $\mathrm{s}, \omega$ is the flow rate calculated for the full cross-section of the equipment in $\mathrm{m} / \mathrm{s}$.

Heat balance equation

$$
c_{g} \frac{d\left(T_{g}\right)}{d \tau}+c_{a} \frac{d\left(T_{a}\right)}{d \tau}+\omega c_{g} \frac{d\left(T_{g}\right)}{d x}=\frac{d\left(Q_{a}\right)}{d \tau}
$$

where $c_{g}$ is heat capacity of a flow in $\mathrm{J} / \mathrm{kg}^{*} \mathrm{~K}, c_{a}$ is heat capacity of an adsorbent in $\mathrm{J} / \mathrm{kg} * \mathrm{~K}, T_{g}$ is the temperature of flow in $\mathrm{K}, T_{a}$ is the temperature of adsorbent in $\mathrm{K}, \tau$ is time in $\mathrm{s}, \omega$ is the flow rate calculated for the full cross-section of the equipment in $\mathrm{m} / \mathrm{s}, Q_{a}$ is heat of sorption / desorption in $\mathrm{J} / \mathrm{kg}$.

Heat-transfer equation

$$
c_{a} \frac{d\left(T_{a}\right)}{d \tau}=\alpha f^{*}\left(T_{g}-T_{a}\right)+\frac{d\left(Q_{a}\right)}{d \tau}
$$

where $c_{a}$ is heat capacity of an adsorbent in $\mathrm{J} / \mathrm{kg} * \mathrm{~K}, T_{a}$ is the temperature of adsorbent in $\mathrm{K}, T_{g}$ is the temperature of flow in $\mathrm{K}, \alpha$ is heat-transfer rate in $\mathrm{W} / \mathrm{m}^{2} \times \mathrm{K}, \tau$ is time in $\mathrm{s}, Q_{a}$ is heat of sorption / desorption in $\mathrm{J} / \mathrm{kg}, f^{*}$ is reduced area of heat-transfer in $\mathrm{m}^{2} / \mathrm{kg}$.

Mass-transfer equation

$$
\frac{d\left(d_{a}\right)}{d \tau}=\beta\left(d_{g}-d_{a}^{*}\right)
$$

where $d_{a}$ is moisture content of adsorbent in $\mathrm{g} / \mathrm{kg}, \tau$ is time in $\mathrm{s}, \beta$ is mass-transfer rate in $1 / \mathrm{s}, d_{g}$ is moisture content of air in $\mathrm{g} / \mathrm{kg}, d_{a}^{*}$ is adsorption equilibrium value. The equilibrium moisture balance equation of the adsorbent (moisture sorption polytherm)

$$
d_{a}^{*}=f\left(p_{g}, T_{a}\right)
$$

where $d_{a}^{*}$ is adsorption equilibrium value, $p_{g}$ is partial pressure of water vapor in $\mathrm{Pa}$, $T_{a}$ is the temperature of adsorbent in $\mathrm{K}$.

At the first stage of column A regeneration (Stage 1) all compressed air flow downstream of a high temperature compressor passes through the column, heating the adsorbent. 
As the temperature increases, the adsorbent's ability to hold moisture decreases, causing the process of desorption of moisture into the flow of a hot unsaturated air (Fig.3).
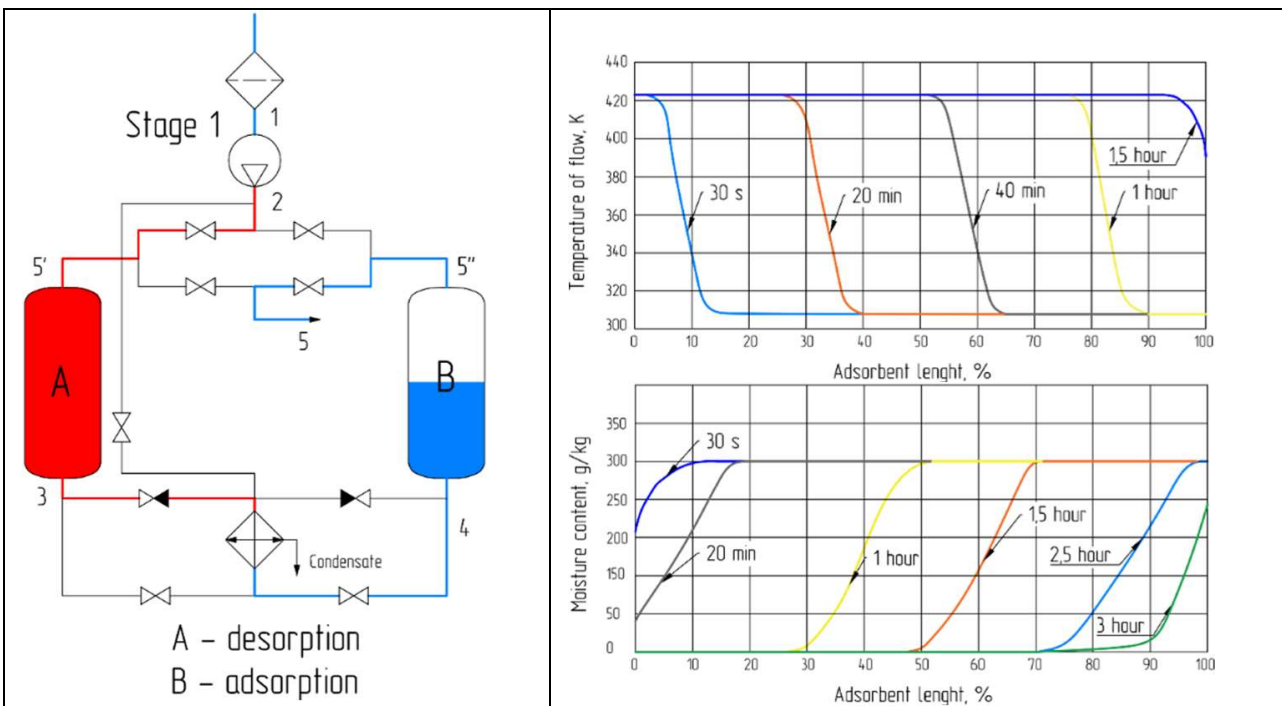

Figure 3. Stage 1 - Regeneration of the adsorbent of column A. The dynamics of the fronts of the air temperature $T_{g}$ and moisture content of the adsorbent $d_{a}$

The calculations of the hot flow desorption process in column A make it possible to observe the movement of the air temperature fronts $T_{g}$ and moisture content of the adsorbent $d_{a}$ along the column A during the process of the adsorbent regeneration. The estimated time of complete desorption consistent with the average parameters of serial desiccants and lasts 3 hours (fig. 3).

The second stage of the regeneration of column A (stage 2) includes cooling the adsorbent to the initial temperature. Cooling is carried out by a part of the flow of precooled compressed air in the heat exchanger with a proportion of flows of $50 \%$ by $50 \%$. 


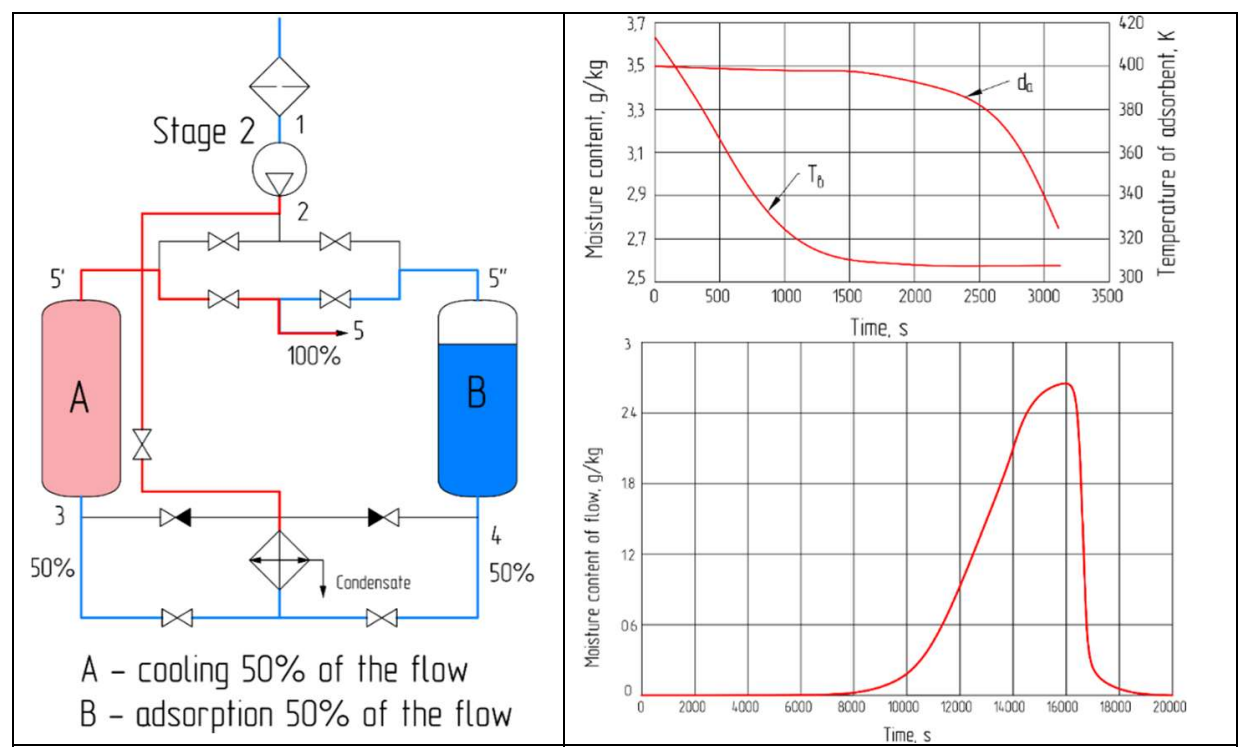

Figure 4. The dynamics of the cooling process of the adsorbent $T_{a}$ and the moisture content at the outlet of the equipment $d_{g}$ at the cooling stage in column

A (Stage 2)

The dynamics of the adsorbent cooling process can be observed by reducing its temperature. From a certain point in the cooling time, the moisture content of the air at the outlet $d_{g}$ begins to decrease, which indicates the resumption of the adsorption process, which is not allowed at this stage. Thus, the cooling stage of column A should be stopped in 25 minutes. The column parameters are fully consistent with the initial switching conditions for the next cycle.

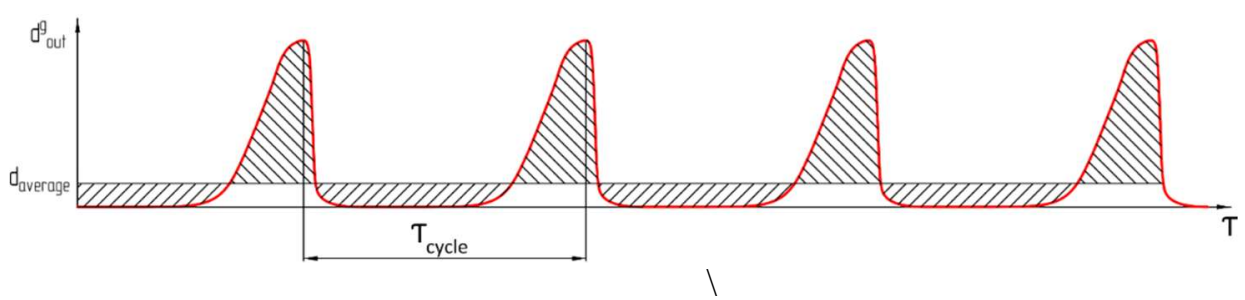

Figure 5. Short-term increase in humidity of dried air $d_{g}$ in each regeneration cycle.

Here, it should be noted that at the outlet of the desiccant there is a short-term increase of the humidity of the dried air $d_{g}$ (fig. 6), caused by mixing of a completely dried part of $50 \%$ of the air in column B and $50 \%$ of the air from column A, which has a humidity corresponding to the dew point temperature after the cooling heat exchanger. A short-term increase in flow humidity is observed on each regeneration cycle. 
At the stage 3, column B continues the process of dehumidification of the full air flow from the compressor, and column $\mathrm{A}$ is in standby mode for switching the cycle. The total estimated time of the cycle was 4,0 hours.

\section{CONCLUSIONS}

The calculations of the processes of adsorption drying of compressed air and regeneration of the adsorbent by compression heat made it possible to examine in detail the dynamics of heat and moisture transfer processes at three stages or the technological cycle.

The estimated time of the complete drying and regeneration process cycle was 4,0 hours, which consistent with the average parameters of the serial desiccants.

The considered scheme of adsorption desiccant with compression heat regeneration make it possible to provide a sufficiently stable temperature of the dew point of the dried air, which given the short-term increases in flow humidity does not exceed $3^{\circ} \mathrm{C}$ at the level of $-40^{\circ} \mathrm{C}$ dew point.

\section{NOMENCLATURE}

$C \quad$ heat capacity $(\mathrm{J} / \mathrm{kg} \times \mathrm{K})$

$\omega$ flow rate $(\mathrm{m} / \mathrm{s})$

$\beta \quad$ is mass-transfer rate $(1 / \mathrm{s})$

$d \quad$ moisture content $(\mathrm{g} / \mathrm{kg})$

$Q \quad$ heat of sorption / desorption $(\mathrm{J} / \mathrm{kg})$

$T$ temperature (K)

$\tau \quad$ time (s)

$\alpha \quad$ heat-transfer rate $\left(\mathrm{W} / \mathrm{m}^{2} \times \mathrm{K}\right)$

$d_{a}^{*} \quad$ adsorption equilibrium value $(\mathrm{g} / \mathrm{kg})$

$P \quad$ partial pressure of water vapor $(\mathrm{Pa})$

\section{REFERENCES}

1. V. V. Kozlov, V. S. Shadrin, and A. A. Podchufarov, "Express analysis of technological processes of compression and drying of wet air at the stages of design and operation of compressor stations," AIP Conference Proceedings 2141, 030029, 1-11 (2019).

2. Podchufarov A. A. et al. Experimental Study of the Possibility of Using Composite Adsorption Materials for Compressed Air Dehumidification Plants //Chemical and Petroleum Engineering. - 2020. - C. 1-7.

3. Podchufarov A. A. et al. Overview of the methods of compressed air purification and dehumidification //Kholodilnaya Tekhnika - 2020. - C. 2-6.

4. I.V. Avtonomova «Compressor stations and installations» Part 2 «Gas treatment methods at compressor stations». M. - The publishing house of BMSTU, 2011. - P. 61.

5. N.V. Keltsev. Basics of adsorption technologies / N.V. Keltsev $-2^{\text {nd }}$ ed. - M.: Chemistry, 1984. - P. 592.

6. E. M. Strizhenov, A. A. Zherdev, R. V. Petrochenko, et al., "A study of methane storage characteristics of compacted adsorbent AU-1," Chem. Petrol. Eng., 52, No. 11-12, 838-845 (2017).

7. E. M. Strizhenov, A. A. Zherdev, A. A. Podchufarov, et al., "Capacity and thermodynamic nomograph for an adsorption methane storage system," Chem. Petrol. Eng., 51, No. 11-12, 812-818 (2016). 
8. Chugaev S. S. et al. Fire-and explosion-safe low-temperature filling of an adsorption natural gas storage system //Chemical and Petroleum Engineering. 2017. - T. 52. - №. 11-12. - C. 846-854.

9. V.V. Kozlov, M.A. Rakhmanov, V.S. Shadrin. Method and program to calculate heat and mass transfer process during adsorption drying of compressed air. Machines and plants: design and exploiting. 2017. №3. P. 4654. 